Tesis. Año 14, 13(16), 2020, 43-64

\title{
Las múltiples caras de Juan Santos Atahualpa
}

\author{
José Luis Villanueva Victorio \\ anunasika@hotmail.com
}

\section{Resumen}

Este artículo analiza las tres tendencias de los estudiosos al tratar del personaje histórico Juan Santos Atahualpa: la versión franciscana, la versión académica (histórica, etnológica, periodística, etc.) y la versión oral (recogida por Enrique Casanto). Asimismo, distinguimos las características de cada vertiente y hacemos una evaluación crítica. El objetivo del estudio es precisar la figura del héroe y valorar su importancia en la historia del Perú.

Palabras clave: tendencia, evaluación, héroe, historia.

\begin{abstract}
This article analyzes the three tendencies of scholars when dealing with the historical character Juan Santos Atahualpa: the Franciscan version, the academic version (historical, ethnological, journalistic) and the oral version (collected by Enrique Casanto). Likewise, we distinguish the characteristics of each slope and make a critical evaluation. The objective of the study is to specify the figure of the hero and assess its importance in the history of Peru.
\end{abstract}

Key words: rend, evaluation, hero, story. 


\section{Las múltiples caras de Juan Santos Atahualpa}

\section{Introducción}

La descripción física y psíquica de Juan Santos Atahualpa se la debemos básicamente a los rumores, generalmente de segunda mano, recogidas en las misivas de los franciscanos. El mismo Rebelde luego de unos años escribió algunas cartas en la que exponía su programa político y su doctrina religiosa, dirigidos al virrey Manso de Velasco y al provisor; mas tal vez en el trayecto se perdieron o fueron destruidas. Se sabe también por la versión franciscana que dos jesuitas se entrevistaron con el inca en 1745, pero no dejaron nada escrito; asimismo los padres fray Francisco Otazuo, fray Salvador Pando y al hermano prior Francisco Suarez lo buscaron en Quimirí y se quedaron varios días en compañía del Rebelde, mas sus impresiones son demasiado escuetas, de modo que todo lo que sabemos de Juan Santos Atahualpa es indirecto y conjetural.

Este carácter casi inasible de Juan Santos Atahualpa no ha sido razón para evitar ser objeto de polémicas. Se puede decir que ha habido tres tendencias en la historia del Perú. La primera es una concepción negativa de raíz franciscana (José Amich, José de la Riva Agüero, Fernando Rodríguez Tena, P. Bernandino Izaguirre, P. Dionisio Ortiz, etc). La segunda concepción es académica, algunas veces elogiosa, nacida de los postulados indigenistas, pues redime la figura del rebelde como un héroe invencible y patriota (Francisco Loayza) y otras veces, despectiva (Vargas Ugarte). Entre estos dos extremos, en mayor o menor medida, en el mejor caso, en una postura conciliadora u objetiva, vacilan algunos estudiosos desde enfoques históricos (Daniel Valcárcel, Flores Galindo, Juan José Vega, etc.), perspectivas antropológicas o etnológicas (Stefano Varese, Fernando Torres López, Alonso Zarzar) y periodísticas (Mario Castro Arenas). Una tercera y última tendencia es la apoyada en la oralidad, básicamente proveniente de la etnia de los asháninkas, quienes no reconocen a Juan Santos Atahualpa como un foráneo de los andes, sino un líder amazónico con 
una vasta genealogía sostenida por la tradición oral. (Pablo Macera y Enrique Casanto).

A continuación desarrollaremos la primera tendencia, que podríamos denominar la visión franciscana acerca del indio rebelde. Seguiremos el orden cronológico.

\section{La visión franciscana}

Esta postura nace en el contexto de las misiones franciscanas iniciadas casi desde el periodo de la conquista y se caracteriza por su carácter eminentemente letrado. Las misiones necesitaban de un espacio que facilitara la penetración en el área selvática y por ello se creó el Convento de Santa Rosa de Ocopa, situada en el valle de Jauja, cuya posesión oficial ocurrió en 1725, convertida luego en Colegio de Propaganda Fide en el año de 1758. Esta institución tuvo su primer cronista o escritor del Colegio en el padre José Amich (nacido tal vez en 1711). Su manuscrito redactado en el año 1771, es decir, casi 30 años después de iniciada la rebelión y publicado en París el año 1854 es el primer texto que recuenta los episodios de la rebelión de Juan Santos Atahualpa. En su compendio José Amich narra en los capítulos XXVI, XXVII, XVIII y XIX la irrupción del rebelde en el contexto de la evangelización.

La investigación del padre Amich empieza con un solemne lamento por las pérdidas de las conversiones de Tarma, el Pajonal y Sonomoro. Desde una perspectiva evangelizadora y cristiana concibe la rebelión como un castigo divino. El contexto dibujado antes de la rebelión es seráfico, o sea, las conversiones de Tarma y Jauja en el año de 1742 disfrutaban de una condición florida e inmejorable. Fueron los indios ingratos, quienes por su hipocresía permitieron la incursión, proselitismo y posterior entronización del Rebelde. Afirma también que Juan Santos Atahualpa viajó a España como sirviente de un jesuita. Volvió al Perú "más ladino de lo que conviniera" (Amich, 1988, p. 167). Asesinó a un hombre en Huamanga y huyó a la selva para evadir la justicia. Por el mes de mayo se encontró con el curaca Mateo Santabangori en Quisopango y allí se proclamó inca. Para su descripción física y psicológica José Amich utilizó el primer testimonio español sobre el Rebelde que encontró en el archivo del Convento de Santa Rosa de Ocopa. Nos referimos a la experiencia del padre fray Santiago Vázquez de Caicedo, conversor del pueblo de San Tadeo, quien buscó al Caudillo el 2 de junio de 1742. A las cinco de la tarde ingresó en Simaqui, llamado también Quisopango. Fue recibido por un grupo de indios formados en media luna. Al poco rato apareció el Rebelde protegido por los indios, que le quitaron el bastón al padre. Asombró al fraile su fluido español. Juan Santos Atahualpa entonces manifestó su intención de componer su reino inca, con ayuda de su pariente inglés, que venía por el mar. Añadió a su escueto programa político revolucionario el establecimiento de un clero indio. 
Los hechos posteriores narrados por Amich han servido como base histórica para los futuros estudiosos. En su narración la postura franciscana es clara: Juan Santos Atahualpa es tildado explícita y constantemente como "embustero, pretenso inca, fingido inca, intruso inca", entre otras descalificaciones y sus seguidores son tildados de "bárbaros e infieles". José Amich configura asimismo la catadura moral del Rebelde con otros documentos franciscanos. Nos referimos a la misiva escrita por fray Manuel del Santo y fray Domingo García desde Pichana al Comisario de misiones fray José Gil Muñoz fechada el día 2 de junio de 1742. En esta carta — publicada por Francisco Loayza en 1942- se afirma que el Caudillo procede del Cuzco, donde ha dejado hermanos. Su edad es poco más de 30 años y su ánimo es recuperar la corona que le arrebataron Pizarro y los españoles.

El mérito de José Amich es ver la rebelión como parte de una historia más extensa: la historia de las misiones. Reúne la información dispersa de los sacerdotes y las inserta en una continuidad espacio-temporal. Les confiere una significación cristiana: el movimiento de Juan Santos Atahualpa constituyó un castigo divino que se expresó en una interrupción en el proceso de evangelización porque Dios permitió que un delincuente y un asesino engañara a una fingida grey que prefirió la barbarie a la civilización. Su balance es negativo: por culpa de la rebelión las misiones se perdieron.

Otro ilustre representante de la visión franciscana es el intelectual limeño José de la Riva Agüero y Osma (1885-1944). En Paisajes peruanos (1955) redactado en 1912 el autor califica la rebelión de Juan Santos Atahualpa como "ensayo algo bufo de restauración indígena, que fue como el preludio de la rebelión de Condorcanqui”, (Riva Agüero, 2010, p. 175). Repite la versión franciscana acerca de que Juan Santos Atahualpa fue un indio cuzqueño y prófugo de la justicia por asesinato. No obstante, le concede una precursoría a regañadientes en el proceso de la independencia del Perú anticipándose a Túpac Amaru II. El mismo autor en su libro Los franciscanos en el Perú y las misiones de Ocopa elogia el Convento de Ocopa como una entidad que cumple una misión evangelizadora y civilizadora. En efecto, para Riva Agüero, Juan Santos Atahualpa destruye y saquea pueblos, no los libera. La evangelización no solo es una empresa de salvación de las almas infieles, sino es un proceso civilizatorio. La rebelión es un retroceso, una interrupción en el progreso.

Por otra parte, el R. P. Dionisio Ortiz en su Reseña histórica de la Montaña del Pangoa, Gran Pajonal y Satipo (1960) continúa la postura franciscana y repite en buena cuenta la versión de José Amich: Juan Santos Atahualpa es un destructor del estado "floreciente" de las misiones. Afirma también la condición de sirviente de jesuitas, asesino y perseguido por la justicia. En su narración destacan los calificativos negativos. La rebelión es denominada "trastorno" (Dionisio, 1960, p. 51), el rebelde es llamado "presumido, intruso, fingido, 
pretendido, de torcidas intenciones" (Dionisio, 1960, p. 52-64) y sus seguidores son "chunchos" o "bárbaros" de un carácter "inconstante y voluble" (Dionisio, 1960, p. 55). Añade que Juan Santos Atahualpa aprovechó dos circunstancias que favorecieron la rebelión: la tensión debido a la guerra intermitente entre España e Inglaterra (1727-1729 reiniciada luego en 1761-1763) y el terremoto de Lima (1746).

\section{La versión académica}

La primera versión histórica es la del militar, político e historiador Manuel de Mendiburu, autor de un vasto diccionario histórico biográfico (1874-1890). Bajo la entrada de Apu-Inca-Huayna Cápac el autor desarrolla la biografía de Juan Santos Atahualpa. Lo denomina indígena, sin dar pie al mestizaje. Llama a los seguidores del Rebelde como "salvajes" o "crecidas turbas de bárbaros" (Mendiburu, 1960, p. 338-340). Sin embargo, su examen es sin duda mucho más objetivo que la versión franciscana. Por ejemplo, ya no explica los triunfos de Juan Santos Atahualpa, como hace José Amich como un castigo divino, sino que encuentra fallas técnicas, estratégicas y logísticas en el ejército español. Así, aclara que la derrota sufrida por la guarnición española en Quimirí padeció de hambre por no prever que los víveres se corrompen con más facilidad en el clima selvático, además de que su localización careció de inteligencia, pues se situó en la ribera del río, es decir, en un lugar vulnerable a las embarcaciones de los indígenas. Se percata de manera muy lúcida de que era imposible combatir y ganar en la selva, pues los guerreros de Juan Santos Atahualpa atacaban con sus flechas y huían. Asimismo, da y enfatiza datos interesantes, como que Juan Santos Atahualpa mandó a matar a Antonio Gatica, su maestre de campo, y a otros amigos cercanos por sospechas de traición (Mendiburu, 1960).

En 1942, aparece otra perspectiva histórica a cargo de Francisco Loayza. Nos referimos al libro Juan Santos, el invencible (Manuscritos del año de 1742 al año de 1755). Es, en realidad, una recopilación documentaria extraída del Archivo General de Indias de Sevilla y de la Biblioteca Nacional de Lima. No pretende hacer una historia de Juan Santos Atahualpa, sino que sienta las bases de estudio para futuros historiadores. No obstante, el recopilador en sus notas explicativas tiende al elogio hiperbólico, a veces tendencioso o equívoco. Por ejemplo, afirma que Juan Santos Atahualpa desciende de uno de los dos hijos de Atahualpa: Diego y Francisco Atahualpa, cuyas probanzas se encuentran en el Archivo General de Indias de Sevilla (Sección, Patronato. Legajo 28, R. 56), no obstante, no demuestra ningún enlace consistente entre estas probanzas y la persona de Juan Santos Atahualpa. Otra información infundada es su interpretación del porqué los indios del sur y del norte no se unieron a la causa de Juan Santos Atahualpa: la rivalidad sobreviviente entre los seguidores del inca Huáscar y el inca Atahualpa. Una explicación más plausible acerca de ese tema 
la brinda el historiador americano de la Universidad de Wisconsin-Madison, Steve Sterne, quien asevera que tanto en Tarma como en Jauja había poderosas familias andinas (los Astocuri, los Apolalaya, los Limaylla), que eran aliadas de corregidores y funcionarios españoles. Incluso el gobernador don Benito Troncoso de Lira y Sotomayor estaba casado con una cacica, doña Teresa de Apoalaya. Los curacas andinos habían patrocinado las misiones en la ceja de selva y adquirido tierras. ¿Qué iban a ganar aliándose a un indio foráneo, arriesgándose a perder su situación privilegiada? (Stern, 1990, p. 79-80).

En 1946 se publica el libro Rebeliones Indígenas de Daniel Valcárcel. Este texto es de índole histórico y desarrolla la rebelión de Juan Santos Atahualpa dentro de un movimiento más vasto, inmersa en una corriente de insurgencia nacional indígena. Un gran mérito de este autor es haber incluido la descripción de los campas, es decir, de los asháninkas, quienes conformaron, en gran medida, las huestes de Juan Santos Atahualpa. Así, traza sus características físicas, la vestimenta, sus comidas y bebidas, su genio o naturaleza. El historiador Valcárcel es un autor más objetivo e imparcial que Francisco Loayza. Afirma, con razón, que no existe ninguna prueba del entronque familiar de Juan Santos Atahualpa con el inca Atahualpa. Recoge el rumor de que el Líder había contactado previamente con los ingleses y enfatiza la aparición del vicealmirante Jorge Anson por las costas del virreinato por los años del inicio de la rebelión. Asimismo, acepta la educación jesuita recibida por el Caudillo (por ello no se opuso a la evangelización de los indios en la selva y tuvo una clara preferencia por ellos). No obstante, no acepta el linaje inca de Juan Santos Atahualpa. Al explicar las razones de su éxito entre los indígenas selváticos dice que "su fingida prosapia y su fuerte personalidad lo hizo imponerse fácilmente" (Valcárcel, 1946, p. 52). Narra básicamente las vicisitudes de la rebelión, ya recogidas por José Amich, pero sin juicios de valor negativos o a favor. Recoge las variadas versiones de la muerte de Juan Santos Atahualpa, como había hecho Francisco Loayza, todas coincidentes en que la muerte del líder ocurrió en Metraro.

E1 historiador y sacerdote jesuita Rubén Vargas Ugarte (1886-1975), en su Historia General del Perú, IV (1966) relativiza la rebelión de Juan Santos Atahualpa. Incluso cree que no merece esa denominación, porque su lucha se restringió a una zona poco habitada y conocida, en los márgenes de la civilización y no conllevó mayores complicaciones. Ha ocurrido un "espejismo histórico” (Vargas, 1966, p. 208). Además, descree que haya tenido una formación jesuita, pues su nombre y apellido no aparecen en la relación de alumnos del Colegio de Caciques del Cuzco. Su supuesto viaje a Europa es inverosímil, ya que los jesuitas no solían tener sirvientes y menos acostumbraban a llevarlos a otros países. Su fama de asesino de jesuitas en el Cuzco y prófugo de la justicia tampoco es probable: no existen registros en la historia de la orden y en las relaciones de esa época en que se asentara semejante caso. En otras palabras, la fama de indio educado por jesuitas, cosmopolita y asesino es meramente 
conjetural, acaso falsa. Y que si su sublevación es más célebre y rodeada de misterio que otras sublevaciones anteriores, como la de Vélez de Córdova, por ejemplo, se debe a "escritores o excesivamente crédulos o parciales en demasía" (Vargas, 1966, p. 208).

La posición de Vargas Ugarte peca de extrema y de mezquina en algunos puntos. Juan Santos Atahualpa es un antecedente de la rebelión de Túpac Amaru II, un "preludio" como reconoció el mismo Riva Agüero y su historia debe inscribirse dentro de un largo proceso de insurrecciones que afectó el siglo XVIII (Stern, 1990, p. 50-51). Su crítica de que su grito de libertad y autoproclamación como inca ocurrió en un lugar no ganado "para las comarcas de la civilización” (Vargas, 1966, p. 208) es una afirmación que contiene implícitamente un prejuicio, ya superado hace décadas, acerca de la existencia de culturas superiores y de culturas inferiores, de culturas civilizadas y de bárbaras. Ignora también el historiador Vargas Ugarte que la zona en que ocurrió la rebelión fue en sus tiempos "una pieza clave en el circuito económico de los andes centrales" (Santos, 1992, p. 103). Asimismo, acota que la sublevación no tuvo mayores complicaciones, aunque todo parece indicar que el virrey Marqués de Villagarcía fue destituido por su fracaso al enfrentar la primera fase de la rebelión (Vega, 1981, p. 358 y Orellana, 1974, p. 526).

Desde una perspectiva antropológica, etnográfica e histórica Stefano Varese (1939) publica su libro La sal de los cerros. Resistencia y utopia en la Amazonía peruana (1968). Distingue dos tipos de acontecimientos durante este siglo: 1) Más o menos los primeros treinta años del siglo, que fueron una prolongación de la exploración geográfica y de los intentos de evangelización iniciados en el año de 1595 por el jesuita Font, continuados por los franciscanos (se descubre el Gran Pajonal en 1733 por el franciscano La Marca) y; 2) la reacción violenta de los indígenas respecto a la evangelización franciscana y la penetración de los colonos españoles al territorio de la Selva Central (Varese, 1968, p. 99). Ya dentro de estas primeras décadas había habido reacciones violentas contra los franciscanos, de parte de los piros y mochobos; no obstante, también se habían fundado varias misiones, como las de Jesús María, San Tadeo de los Antis, Nijandaris, Metraro y Eneno, futuros escenarios donde se desarrollaría la rebelión.

Creo que podemos afirmar sin temor a equivocarnos que Varese es uno de los autores más completos y sistemáticos al historiar la rebelión de Juan Santos Atahualpa, junto con Arturo E. de la Torre. Tiene una visión integral y es proclive a distinguir etapas en el flujo de los acontecimientos históricos, identificar las posturas ideológicas contrapuestas de los autores que han tratado el tema y, sobre todo, conoce a las etnias selváticas desde dentro gracias a la convivencia y no al mero academicismo. Por ejemplo, es uno de los primeros en señalar el denominado mesianismo de Juan Santos Atahualpa en virtud a su ideal de li- 
beración de base religiosa mediante un movimiento de unidad panindígena sin precedentes (que luego llevaría a extremos postizos Alonso Zarzar), superando de esa manera la mera óptica historicista. Asimismo, identifica las dos grandes posturas opuestas en torno al héroe: la versión franciscana y la historiografía oficial republicana y contemporánea, y la otra, la del indigenismo de los años 30 del siglo XX (Varese, 1968, p. 103). Sin duda es más agudo que sus antecesores. Para dar una muestra intenta explicar porqué Juan Santos Atahualpa escoge a Simaqui como el mejor lugar para dar su grito de libertad: allí se concentraban muchas de las familias forzadas a vivir en las misiones por los franciscanos, además de su ubicación estratégica inexpugnable protegida por el río innavegable Shima y su lejanía de las misiones del Perené y Chanchamayo. También desenmascara con claridad acerca de las imputaciones de asesino de jesuitas reduciendo el argumento al siguiente: un testigo (José Bermúdez) declara que un tal indio (Basilio Huamán) le dijo que otro indio (Juan Cosco) le había dicho que Juan Santos Atahualpa es prófugo de la justicia, en otras palabras, una información indirecta. Duda, además, de su supuesta declaración pública y oratoria de rebeldía, que fue más bien tácita o una mutua comprensión solidaria y revanchista entre subordinados hastiados que una encendida declaración retórica y sociológica, porque en la Selva no había ni minas ni obrajes como en la sierra (Varese, 1966, p. 104-106). No obstante, Santos Granero afirma que las etnias selváticas no estaban exentas de la explotación y el control en diversos planos (moral, religioso y económico) que se aplicaban a los indios de la sierra (Santos, 1992).

En cuanto al curso de los acontecimientos históricos Varese discierne dos bloques: 1) los primeros diez años, es decir, desde 1742 hasta 1752, periodo caracterizado por las escaramuzas - es en realidad, el nombre adecuado a estos enfrentamientos, pues nunca hubo una batalla estricta, sino trampas, asedios y asechanzas en las trochas del bosque - entre las tropas realistas y los guerreros asháninkas y 2) inicia en 1752 con el retiro de Juan Santos Atahualpa y sus indios de Andamarca hasta un tiempo indefinido. Es el periodo de los resultados, por el cual las etnias de la Selva Central disfrutaron de la independencia que el rebelde consiguió al alejar a los misioneros y a los colonos. Ahora bien, si podemos hacer una crítica al examen de la obra de Varese es la escasa importancia que da al elemento de la oralidad en la configuración de la historia de la rebelión. Solo al final del capítulo III, al exponer las diferentes versiones de su supervivencia y la muerte del líder, destaca que a los indios de la selva no les importa mucho la fecha de la desaparición física de su inca, pues para ellos no ha muerto: esperan su regreso y su espíritu sigue vivo en el recuerdo colectivo.

E1 historiador Juan José Vega (1932-2003) en su Historia General del Ejército Peruano. Volumen I. Tomo III (1981) asevera que la rebelión de Juan Santos Atahualpa tuvo un trasfondo social: los campas o asháninkas sumados a otras etnias de menor número habían aceptado, al menos de una manera superficial, 
el sometimiento a las misiones franciscanas y a la religión cristiana, pero la conducta de los sacerdotes no era consecuente con los principios que predicaban y por eso, sumado al amor a una vida casi nómada y sin explotación, aceptaron de buena gana seguir a un indio foráneo. Critica al historiador Vargas Ugarte por negar la formación jesuita de Juan Santos Atahualpa, pues a él le parece indudable y evidente. Acerca del viaje a Europa censura también que el historiador jesuita lo haya tildado de inverosímil, pues ni siquiera José de la Riva Agüero negó tal posibilidad. Juan José Vega tampoco vacila en afirmar que el rebelde viajó a Europa, tal vez por sus propios medios, tal vez subvencionado por revolucionarios criollos. Destaca el proyecto unificador de Juan Santos Atahualpa, es decir, la unidad política de todos los naturales del Perú. De momento, había logrado lo impensable: la unidad de las naciones de la Selva Central (Vega, 1981, p. 340). Así, no solo agrupó a los asháninkas con los amueshas, sino que también unió a los piros, etnia con una fama bien ganada de ferocidad; a los mochobos, nación con semejante fama de indómitos, a los simirinches y a los cunibos. Aspiró ganar a su movimiento a los andinos y a los mestizos. No se olvidó tampoco del componente negro. Incluso, un ex esclavo de las reducciones fue su primer lugarteniente, el negro Antonio Gatica. Los cuadros de dirigencia de su organización eran, generalmente, alumnos aplicados de las misiones. Después de relatar la historia de la rebelión, siguiendo la secuencia narrada por José Amich, señala que la muerte de Juan Santos Atahualpa no necesariamente ocurrió en 1756, año en que el brigadier Pablo Sáenz de Bustamante llega a Quimirí y no es atacado por las huestes del rebelde. Basándose en Cosme Bueno y Stefano Varese conjetura que para los años de 1770 Juan Santos Atahualpa vivía, pero ya no era el guerrero maduro de antaño, sino el patriarca anciano.

Mario Castro Arenas publicó en 1973 La rebelión de Juan Santos. Es el primer libro que trata de manera exclusiva y no episódica sobre la historia del rebelde. No es solo un capítulo más como en los investigadores precedentes. Es un texto impactante y de divulgación, que utiliza de manera sintética la información histórica y etnológica obtenida hasta su momento. Tuvo el mérito de poner otra vez al rebelde de la Selva Central en el ojo de la tormenta. Explica más que otros la probable conexión inglesa de la rebelión de Juan Santos Atahualpa con la exposición de las ideas de Thomas Gage de ayudar a los indígenas americanos a liberarse del yugo español para el beneficio inglés con la mención del proyecto Occidental (Western Design). Enfatiza la predilección del rebelde por los jesuitas y parece inclinarse por su formación en La Compañía, siendo un indio aculturado y de un cristianismo especial. En este sentido acepta la tesis de Varese de que Juan Santos Atahualpa era un caudillo religioso-político. Añade en su colofón documentos históricos, como cartas del virrey Conde de Superunda o una relación de la doctrina, errores y herejías de Juan Santos Atahualpa escrito en 1750 por un franciscano llamado Joseph de San Antonio, comisario de las misiones de infieles del Cerro de la Sal, Jauja, Huánuco y Cajamarquilla, 
quien lo presenta como "el Inimicus homo del Evangelio" (Castro, 1973, p. 14). Sus conclusiones son interesantes, pues pide revaluar el significado histórico de la rebelión, subestimada generalmente por los historiadores. Reconoce los vacíos heurísticos acerca del personaje y reclama una mayor investigación en los registros de todos los colegios regentados por los jesuitas, como el Colegio Real de San Bernardo para aclarar su filiación con la Compañía. Asimismo, solicita la exploración de los archivos británicos del Foreigne Office para clarificar los nexos del caudillo con su aliado "el inglés, su pariente". Advierte también que Juan Santos Atahualpa debe ser inserto dentro de los movimientos mesiánicos de América del Sur.

Alonso Zarzar publica en 1989 su libro Mito, utopia y milenarismo en el pensamiento de Juan Santos Atahualpa. Su objetivo es investigar la ideología del líder. Esta ideología, que el autor concibe como la más compleja desde la Conquista, es la síntesis de tres elementos: el milenarismo cristiano, la utopía andina y la mitología amazónica. El milenarismo cristiano del que habla se refiere a las ideas milenaristas de Joaquín de Fiore, llevadas al Perú por los franciscanos; la utopía andina alude al mito de los ciclos conocidos como Pachacuti y de Inkarri, y, por último, la mitología amazónica de Pachakamáite entre los asháninkas y el dios Tsla de la nación de los piros. Anota certeramente que si bien el movimiento nunca fue vencido, tampoco tuvo éxito. Amplía la explicación de la organización de las reducciones franciscanas, el espacio de la Selva Central como refugio para los andinos huidos de los obrajes y de las minas y añade a la causa de la insatisfacción de las etnias la casi ignorada exposición a las epidemias que produjo efectos devastadores en la población indígena (Zarzar, 1989, p. 30-31). Una novedad en su estudio es extender el examen de los amueshas y revalorizar su importancia en la rebelión: Juan Santos Atahualpa, autoproclamado Hijo del Sol, se asentó más tiempo entre ellos, porque tenían un panteón divino semejante a los incas; por ejemplo, ambos adoraban al sol, el dios Yompor era el dios Inti y el rebelde, su hijo. Para investigar la ideología de Juan Santos Atahualpa, Alonso Zarzar elabora una serie de perfiles ideológicos, que intentan captar una evolución en sus ideas, basado en las informaciones indirectas de fuente franciscana que poseemos. El primer perfil es la concepción que tiene el propio rebelde de sí mismo: hacia el inicio de su proclama pública es solo un enviado de Dios y un cristiano humilde; hacia 1747 sigue siendo un enviado de Dios, pero puesto en la tierra para reinar. Es un rey y los sacramentos están incompletos sin él. Hacia 1752 afirma ser hijo de Dios. Es el Dios de América capaz de hacer milagros. El segundo perfil es el rebelde como Inkarri. En 1742 afirma también ser hijo del inca que Pizarro degolló en el Cuzco, que deja 3 hermanos allí, que desea ser rey y coronarse en Lima. Lo acompaña un anciano, que dice es su ministro y que tiene 130 años. Hacia el año 1747 declara que Dios castigará la tierra con fuego y que Huayna Cápac lo nombró monarca de su reino. Los matrimonios que oficia son válidos y que no 
hay necesidad de cura. En 1752 señala que la Virgen María está en España y que él es hijo de la virgen Sapa Coya. Mantiene 12 hombres armados con sables, como su vigilancia particular. El tercer perfil es producto del sincretismo de un cristianismo milenarista y apocalíptico, asociado de manera forzada a los pachacutis y las deidades amazónicas. Alonso Zarzar enlaza las tres edades del joaquinismo (Edad del Padre, Edad del Hijo y Edad del Espíritu Santo) con las alusiones que en sus discursos hace el rebelde, con el Sol, Huayna Cápac y con el Espíritu Santo. Todo parece más bien un esquema forzado y demasiado complejo para un líder indígena del siglo XVIII, que acaso solo quiso obtener poder. Es una gran extrapolación. Además, olvida que Juan Santos Atahualpa más tuvo de jesuita que de franciscano y que, por lo tanto, las doctrinas milenaristas de Joaquín de Fiore y sus eras aplicadas a la rebelión resultan impuestas o fingidas: el líder era claramente antifranciscano, si hemos de confiar en las mismas informaciones franciscanas acerca de la rebelión. No podemos olvidar que el líder los expulsó de la Selva Central. ¿Cómo entonces iba a usar las categorías de un italiano de la Edad Media, que propuso una observancia extrema de la norma franciscana, es decir, la ideología de un enemigo, de un franciscano, tan lejano en el tiempo y en el espacio? En todo caso, sus especulaciones basadas en las informaciones franciscanas son solo eso: meras especulaciones que se basan en fuentes indirectas.

Desde la University of Wisconsin, el historiador Steve J. Sterne publica Resistencia, rebelión y consciencia campesina en los Andes (1990). Nos informa que a lo largo del siglo XVIII hubo más de cien insurrecciones. Destaca dos momentos en este siglo: el primero, que es la insurrección mesiánica de 1742 iniciada por Juan Santos Atahualpa que infligieron derrotas al poder colonial y solo atinaron a combatir la rebelión mediante fortificaciones que impidieran que los combatientes cruzaran hacia la sierra. Y un segundo momento, desde 1780 a 1782, protagonizado por Túpac Amaru II. Ambos proyectaron la figura de indios nobles desheredados que reclamaban sus derechos reales sobre el reino del Perú. Estas dos etapas constituyen lo que Stern denomina la Era de Insurrección Andina y constituyeron más que meras rebeliones porque abrieron la posibilidad de desatar una insurrección generalizada que revertiera los privilegios coloniales y modificara la estructura del gobierno. Distingue dos tendencias en los estudiosos de la rebelión: 1) los que se centran en el significado que el movimiento tuvo en las poblaciones de las tierras bajas y andinos que habitaban la Montaña Central (Castro) y 2) los que estudian el movimiento en el contexto del trabajo misionero de los franciscanos (Stern: 1990, p. 5153). Afirma que los estudios de la repercusión de la rebelión en los andinos tienen escasas evidencias en la historia tradicional de modo que un examen sólido se reduce en tomar a la rebelión como una insurrección de frontera, sin participación de la sierra y que este estado de las cosas debería extenderse con nuevos aportes. Una información interesante de Stern constituye el dato de que 
Juan Santos Atahualpa, mediante un documento de 1752 provenientes de los archivos del corregidor local (es decir, durante la rebelión) confirma que habría purgado prisión en una isla próxima al Callao, conocida con el nombre de La Piedra durante el gobierno del virrey Castelfuerte, pero no por asesinar a un jesuita, sino por motivos políticos, o sea, cuando realizaba su tarea de azuzar a los curacas andinos a sumarse a su rebelión. Eso explicaría la enigmática frase atribuida a Juan Santos Atahualpa: "Mi casa se llama Piedra" (Stern, 1990, p. 60). Steve Stern es un historiador sistemático y sintético, que tiene la virtud de ver las cosas de manera muy clara, apoyado siempre en estudios históricos. Por ejemplo, a grandes rasgos nos explica que la rebelión de Juan Santos Atahualpa fue un movimiento multiétnico y multirracial, compuesto en parte por desplazados serranos y disidentes negros, que habitaban la Selva Central, refugio tradicional de andinos desarraigados desde tiempos incaicos. Las autoridades intentaron sofocar la rebelión enviando varias expediciones militares, que fracasaron unas tras otras. Incluso envió a uno de los militares más prestigiosos de su momento, el general José de Llamas, que había tenido una actuación destacada en la defensa de la costas virreinales contra Inglaterra. Todas estas derrotas, acompañadas de un menosprecio hacia los "chunchos", fue transformándose en una desmoralización constante, que redujo la estrategia realista a la mera contención defensiva mediante el establecimiento de fuertes o bastiones para impedir las comunicaciones selva-sierra, hasta el punto de que las zonas de Tarma y de Jauja se habían convertido casi en un reducto militar. (Stern: 1990, p. 61). Esta estrategia meramente "pasiva" es vista como una señal de derrota o conformismo en Stern. No obstante, el investigador Joseph Dager Alva al historiar la vida del virrey José Antonio Manso de Velasco en su texto Conde de Superunda (1995) cree que la estrategia meramente defensiva adoptada de una manera deliberada y no por impotencia por el virrey Conde de Superunda, producto de su amplia experiencia bélica, le dio el triunfo final sin luchar, pues hizo consciente al rebelde de su inferioridad bélica y lo desalentó de seguir atacando más pueblos, como Andamarca (Dager, 1995, p. 54).

El principal aporte de Stern es la investigación del impacto de la rebelión de Juan Santos Atahualpa en los Andes. ¿Gozó de apoyo en la Sierra Central? ¿Cómo reaccionaron los andinos al saber de su rebelión? Stern encuentra varias áreas de evidencias de que tuvo una buena acogida. Por ejemplo, durante la expedición de las fuerzas realistas de 1743 los arrieros indios de Huarochiri utilizados para el transporte de carga desertaron. Otra muestra de adhesión ocurrió en 1747 cuando veinte indios andinos, menos uno, abandonaron a un padre franciscano y a sus diez soldados españoles, luego de que estos hubieran intentado adoctrinar inútilmente a los indios de Acón en el sur -la zona cocalera - para luego regresar con indios selváticos y asesinar a todos. El que no huyó fue quien contó la historia. Otra señal de aceptación del Inca fueron sus palabras al ocupar Quimirí en 1743 en las que declaraba explícitamente 
que amaba a los andinos. Los indios de Chanchamayo al saber de la buena nueva hicieron fiesta durante la noche y cantaron tonadas en que proclamaban que tomarían chicha en los cráneos de los franciscanos. A hora bien, la toma y fuga del pueblo andino de Andamarca señala un viraje en los planes del Inca: el enclave andino, que tal vez serviría como punto de entrada y difusión de la rebelión no pudo ser retenido al llegar las fuerzas realistas acantonadas en los valles de Jauja y Tarma. La historiografía franciscana se regodea en afirmar que Juan Santos Atahualpa al no encontrar apoyo de los andinos se desquitó incendiando el pueblo, en otras palabras, lo presentan como un líder vengativo y frustrado. Stern luego de una lectura atenta concluye que sí hubo adhesión de los indígenas (pues solo hubo dos disparos), entró pacíficamente al pueblo y recibió muestras de respeto como el nuevo Inca. Los incendios que provocó al replegarse por la llegada de tropas españolas se produjeron solo en lugares fijos y simbólicos, como la iglesia (Stern, 1990, p. 70). Asimismo, para enriquecer la poca información obtenida solo por las versiones franciscanas, Stern analiza los expedientes criminales de los agentes y supuestos espías al servicio del Inca después de la invasión al pueblo de Andamarca. Se trata de los tres arrieros desorientados, que rezagados en el camino se extraviaron y cometieron la imprudencia de preguntar por el Rebelde a las personas equivocadas, quienes los llevaron a la cárcel. Se trataba de Julián Auqui, Blas Ibarra y Casimiro Alberto. Antes de que los ahorcaran por traición y espionaje, como ejemplo para intimidar a otros posibles seguidores ocultos entre la población, sin ser espías ni soldados del Inca, solo simples arrieros que simpatizaban con la causa libertaria. Finalmente, se interroga acerca del porqué no se extendió la rebelión de Juan Santos Atahualpa en la sierra. Responde que la organización de una insurrección de grandes dimensiones se enfrentaba a dos grandes obstáculos: una red de espionaje efectiva (curas que violaban el secreto de confesión) y la aplicación de la estrategia política de "dividir para reinar" mediante el clientelaje, privilegios a los colaboracionistas, integración de las élites andinas, incorporación de funcionarios indígenas, etc. Stern destaca que la región Tarma-Jauja los grupos de poder estaban conformados por familias indígenas y no indígenas aliadas por matrimonios (por ejemplo, el mismo gobernador don Benito Troncoso de Lira y Sotomayor estaba casado con doña Teresa Apoalaya, que era cacica). En otras palabras, la estructura estatal y las élites autóctonas se habían fusionado con una intensidad singular. De esa manera, la rebelión de Juan Santos Atahualpa atravesaba graves dificultades para contar con la adhesión de los indígenas de las clases dirigentes de las cercanías. Otro punto no menos importante fue la exoneración de la mita a las minas de Tarma. Tales son sus explicaciones acerca del porqué fracasó la rebelión.

Otro estudio importante que ayuda a explicar el éxito de Juan Santos Atahualpa en un sector generalmente tenido como marginal en el Perú, como es la selva, es el artículo del historiador Fernando Santos Granero. En su estudio 
Anticolonialismo, mesianismo y utopía en la sublevación de Juan Santos Atahualpa, siglo XVIII (1992) plantea la idea de que la selva central estuvo ligada a los Andes Centrales como una pieza clave en la economía y es solo con el triunfo de Juan Santos Atahualpa que empiezan los mitos del aislamiento selvático (Santos, 1992, p. 103-106). Propone Santos Granero que los neófitos selváticos estaban siendo incorporados a la economía virreinal en tres modalidades: 1) colonización y explotación de los recursos de la región por parte de los españoles, mestizos e indígenas serranos; 2) trabajo de los neófitos en las tierras y los talleres textiles de las misiones y 3 ) imposición de la obligación del servicio personal, obrajes y repartos (Santos, 1992, p. 106). La colonización se produjo poco después de 1709 cuando numerosas familias españolas de Tarma y Huánuco y familias andinas vecinas establecieron en la selva central haciendas de coca, tabaco y caña de azúcar para producir aguardiente (hacienda Chanchamayo, la hacienda de los Condes de las Lagunas, etc.) Las misiones, según los inventarios, mencionan la existencia de cañaverales y trapiches. Tal vez se dedicaban a la exportación de sus productos a las minas próximas a Cerro de Pasco y exigían a los neófitos trabajar en sus campos. Las mujeres asimismo laboraban en los textiles de las misiones. No hay seguridad, no obstante, al parecer también eran sometidos a una mita en forma de servicio personal. En otras palabras, la población indígena de la selva de las misiones no desconocía la explotación y el abuso de modo que la prédica revolucionaria anticolonial de Juan Santos Atahualpa fue muy bien recibida. Además, hay que sumar que el mensaje mesiánico incaico tampoco era ajeno al mundo selvático. Santos Granero afirma que los Amuesha, Ashaninka, Machiguenga, Piro, Shipibo, Conibo y Cashibo conocían la figura del Inca como un personaje divino o semidivino, con poderes extraordinarios y un papel civilizador. Nos parece que la importancia de este estudio también radica en ocuparse en la cosmovisión de las otras etnias que siguieron a Juan Santos Atahualpa. Por ejemplo, al presentarse el Rebelde como hijo del sol tal vez impactó a los asháninkas y a los amueshas, pues el sol ocupa un lugar central en el panteón de estas culturas. Igual para los cunibos, que llaman al sol Bari inka. Para los amueshas, Juan Santos Atahualpa era el enviado de Yompor Ror, la divinidad del sol y se le conoce hasta ahora como Yompor Santo, hijo del sol. Juan Santos Atahualpa, al parecer actuaba como un cornesha o sacerdote amuesha, pero con una diferencia sustancial: él era un líder político-religioso. Muchos de los corneshas se dedicaban a la forja de hierro y fueron las herrerías las que perduraron después de la rebelión de Juan Santos Atahualpa hasta su destrucción en el siglo XIX.

El historiador Alberto Flores Galindo en su Buscando un inca (1998) inserta la rebelión dentro del contexto de las utopías andinas o mejor dicho como una de sus muchas versiones. Al argumento de que la figura de Juan Santos Atahualpa es elusiva destaca que a la escasez de referencias se contrapone una rebelión que duró más o menos una década y que sorteó el asedio de cinco expediciones pu- 
nitivas del virrey (Flores Galindo, 1998, p. 103). Es decir, para ser un personaje fantasmal su presencia tuvo repercusiones concretas prolongadas. Destaca la importancia que concede a los estudios acerca de la procedencia de los seguidores del Rebelde. Poco después del ataque a Andamarca en 1752 se capturaron a 3 hombres - dos indios y un mestizo - que buscaban a Juan Santos Atahualpa para integrarse a sus filas. Ellos proporcionaron información interesante durante los interrogatorios. Dijeron que había por lo menos un español, que era limeño y desempeñaba el cargo de escribiente; un mestizo cuzqueño, que había sido mayordomo de la Convención, en Cuzco; otro mestizo de Concepción y 600 indígenas flecheros con trajes típicos, tanto de los Andes como de la Selva Central. Destaca también la tendencia a la tripartición de sus ideas: tres grupos raciales (indios, españoles y negros), tres reinos (Angola, España y los Andes), tres edades (la última la del Espíritu Santo). Desde luego que esta tripartición es forzada, por ejemplo, en el asunto de los reinos parece olvidar que Juan Santos Atahualpa también mencionó otro reino (el inglés), cuyo rey lo ayudaría por mar. Se olvida asimismo del mestizaje en los grupos raciales. Advierte la evolución en el pensamiento de Juan Santos Atahualpa y ensaya una explicación de los cambios. Así, distingue que en los comienzos de la rebelión el Inca parece aceptar el cristianismo, pero a medida que pasan los años parece rechazar solo a los franciscanos y cuando se percata de que los andinos y criollos no se aúnan al movimiento el rebelde parece alejarse de la religión católica y adoptar una postura nativista. Otro punto que el historiador intenta responder es el porqué el fuego de la rebelión solo encendió en el Gran Pajonal y no se extendió a todo el Perú. Flores Galindo responde que el mensaje de Juan Santos Atahualpa solo podía atraer a indios desarraigados, huidos de los obrajes y minas, también a los indios de la selva, pero no a los andinos próximos al Cerro la Sal y a los que vivía en la entrada del valle del Mantaro, porque eran regiones ancestrales de los huancas, o sea, de los enemigos tradicionales de los incas. El nombre del inca Atahualpa no concitaba ninguna adhesión. El éxito del Caudillo radicó en el rechazo al mundo occidental representado por los misioneros franciscanos que se empeñaban en implantar un modo de vida que los indios aborrecían: el sedentarismo y la práctica de una agricultura sostenida y permanente. Los indígenas de la selva estaban habituados a cambiar de lugar una vez agotados los recursos naturales. Los franciscanos representaban la muerte de sus dioses tradicionales, pero sobre todo los misioneros traían las epidemias que asolaron a las naciones amazónicas. Ahora bien, ese éxito también contribuyó al fracaso del movimiento que se adscribió exclusivamente a la zona selvática. ¿Para qué iban a viajar a Lima, un lugar extraño y lejano, enfrentados a un ejército profesional con armas de pólvora, si ya habían conseguido su objetivo en el bosque: alejar a los misioneros y eliminar las reducciones?

Por último, el historiador Arturo E. de la Torre en su obra Juan Santos Atabualpa (2004) dedica un texto íntegro a la rebelión y a la peculiar figura del hé- 
roe, tal como en los años 70 había hecho Mario Castro Arenas con una diferencia fundamental: De la Torre tiene una visión histórica más amplia, profunda y sistemática y además posee la virtud de la síntesis. Primero, contextualiza el escenario del imperio español en el orden mundial: una potencia venida a menos con el Tratado de Utrech (1713) y el ascenso de los Borbones en la corona ibérica en reemplazo de los Habsburgo, cuyas reformas tuvieron como objetivo modernizar la administración y reforzar el poder estatal (Torre, 2004, p. 13). La modernización de las instituciones trajo como consecuencia la eficiencia del fisco y, por ende, su voracidad. No tardó en desatarse un amplio descontento en la población en general. En el virreinato del Perú, los indios sufrían intensamente los trabajos compulsivos de la mita y el obraje; pero sobre todo, padecían de los repartos y los impuestos de los corregidores. Estos abusos ocasionaron diversos levantamientos indígenas a lo largo de todo el siglo XVIII. En este proceso se enmarca la rebelión de Juan Santos Atahualpa. El historiador enfatiza la escasa fiabilidad de las fuentes, no obstante, saca en claro dos conclusiones: 1) Juan Santos Atahualpa era un foráneo en el mundo amazónico y 2) su formación intelectual era superior al promedio (Torre, 2004, p. 21). Acota con perspicacia que las versiones franciscanas enfatizan la preferencia del Rebelde por los jesuitas y que esto podría ser una manera sutil de desacreditarlos y que su liderazgo alcanzó la esfera de lo reverencial, en virtud de su ascetismo, su habilidad estratégica, su extraordinaria confianza en sí mismo (Torre, 2004, p. 26- 29). Luego, enfatiza que los estudios históricos han sido más "andinistas" que selvícolas. La Selva ha sido un espacio marginal desde el incanato. El inca Túpac Yupanqui fracasó en la empresa de anexar a los "antis", como los andinos llamaban a las personas oriundas de la selva. Los conquistadores europeos también fracasaron como colonos en la vasta región amazónica. Los franciscanos hicieron entradas misioneras desde 1635, no obstante, la fundación de misiones y de iglesias, el saldo fue negativo por la constancia de los indígenas en asesinar sacerdotes. Pocos años antes de la llegada del siglo XVIII, el padre Comisario General, fray Gabriel Arregui ordenó poner fin a las misiones (Torre, 2004, p. 40). Con la fundación del templo de Ocopa en 1725 las entradas en la selva se reanudaron. La evangelización, no obstante, continuó generando el rechazo de las poblaciones oriundas. Así, en Catalipango se rebeló y asesinó padres franciscanos el cacique Ignacio Torote en 1737, quien huyó hacia las profundidades del bosque. En la captura de los cómplices de Torote intervinieron los que serían los futuros capitanes de Rebelde: el curaca conibo Siabar, el curaca Mateo de Assia y el ex esclavo negro Antonio Gatica, quien capturó a 36 sospechosos, mas no se apresó a Ignacio Torote, y luego este se unió a la rebelión de Juan Santos Atahualpa (Torre, 2004, p. 45). Apunta entre las causas del rechazo a los franciscanos, básicamente, al exceso de doctrinas y sermones más la introducción de enfermedades y epidemias occidentales. 
La línea de los acontecimientos es la misma que han descrito las versiones franciscanas y los historiadores anteriores. Desacredita la supuesta colaboración del imperio inglés en la rebelión, porque los imperios europeos fueron muy conscientes de que apoyar una revolución de un enemigo podía afectarlos a largo plazo por ser un ejemplo negativo para sus propios intereses. Especificando más arguye que el paso del vicealmirante Anson por el Estrecho de Magallanes, fondeando con cinco naves en la isla de Juan Fernández en el año de 1741 obedecía a las acciones de una contienda marítima llamada "guerra de las orejas de Jenkisn”. Las flotas de Vernon irían por el Caribe y las de Anson por la costa occidental para atacar Panamá, pero el fracaso de Vernon obligó a Anson a retroceder y dar la vuelta al mundo. Tales flotillas no podían atacar con éxito puertos importantes; por lo tanto, la alianza entre Juan Santos Atahualpa y los ingleses fue muy improbable. No obstante, tampoco le parece una mentira por la repercusión que podía haber tenido entre las autoridades españolas. En todo caso, él estuvo convencido de ello, sin que se pueda determinar el origen de su afirmación (Torre, 2004). Subraya asimismo el carácter nativista de la rebelión. Una de esas posibles causas podría ser una toma consciencia de la alteridad de los selváticos frente a los extranjeros. Finalmente, el autor realiza una valoración de la rebelión. La revuelta estaba condenada al fracaso: en la irrupción a Andamarca con la ausencia de la adhesión de la población andina el propio Juan Santos Atahualpa se percató de sus limitadas perspectivas de triunfo y el movimiento murió solo. A partir de allí se retiró. El gobierno del virrey no interpretó jamás la rebelión como una amenaza seria y por eso se limitó a estrategias meramente defensivas. La importancia de Juan Santos Atahualpa se funda en su doctrina y en su rica cosmovisión sincrética (Torre, 2004, p. 93-95).

La postura de Arturo E. de la Torre es una de las más equilibradas y juiciosas: evita los apasionamientos y las descalificaciones prejuiciosas. Con conocimientos históricos muy solventes analiza las vicisitudes de la rebelión y refuta las ideas milenaristas de Joaquín de Fiore que Zarzar atribuye a su ideología. El milenarismo que usa Juan Santos no es necesariamente joaquinista, ni el de la tradición judeo-cristiano, sino un milenarismo nacido en un marco socio-religioso que convive con una fuerte desestructuración cultural. Desde luego, sus interpretaciones son posibles. Recordemos que el carácter elusivo del Líder nos abre la puerta solo a meras conjeturas y a la controversia entre esas conjeturas.

\section{La oralidad}

La versión franciscana ha servido de base para toda la elaboración de hipótesis históricas y mesiánicas acerca de la rebelión. La tradición oral de los acontecimientos recogida por los investigadores, básicamente, se centró en las diferentes versiones de la muerte de Juan Santos Atahualpa o en su anticipación sobre los eclipses. La inclusión del estudio de las etnias selváticas de Valcárcel y de Va- 
rese no incluyó sus versiones de la rebelión. En cambio, con el estudio de Pablo Macera y Enrique Casanto se recoge por primera vez en un texto bilingüe la versión de la rebelión de parte de los asháninkas. Pablo Macera se encargó del aspecto histórico y Casanto, como descendiente asháninka, fue el que recogió las tradiciones orales y de su traducción. Nos referimos al texto El poder libre asháninca. Juan Santos Atabualpa y su bijo Josecito (2009), cuyo objetivo es dar a conocer las tradiciones asháninkas acerca de sus luchas por su libertad. Según Pablo Macera, el movimiento de Juan Santos Atahualpa se inscribe en un contexto de rebeliones indígenas amazónicas, es decir, es parte de una tradición de sediciones conocidas, iniciadas tempranamente desde 1637 con la rebelión del curaca Zampati en Quimirí y continuada cada cierto número de años. La sexta rebelión en la Selva Central es la de Juan Santos Atahualpa, en simultánea con los que serían luego sus capitanes: Siabar (1742, curaca de Quisopango) y Perote (1742, curaca conibo). Estas constantes rebeliones permiten constatar que las reducciones estaban lejos de gozar de un estado "florido" o próspero, tal como afirmaban las versiones franciscanas, sino que evidenciaban un malestar latente y un rechazo al modo de vida impuesto por las misiones. Observa Pablo Macera que las etnias selváticas opusieron mayor resistencia a la evangelización que los andinos y que las misiones franciscanas tuvieron menor arraigo y éxito que las misiones jesuitas, no obstante, hay una ausencia de un cuadro comparativo entre estas dos órdenes religiosas. En la obra se destaca las nuevas fuentes de información que utilizó Enrique Casanto: 1. Las memorias familiares diversas. 2. Las entrevistas. 3. Festividades. La memoria familiar en esta sociedad ágrafa desarrolló un lenguaje simbólico mediante figuraciones, que utilizaban dibujos faciales, vinculado a agrupaciones familiares. Estos dibujos aluden a fenómenos de la naturaleza (huracanes, temblores), animales y árboles, aunque también incluyen sentimientos. Las entrevistas fueron realizadas por Casanto durante las décadas de los 80 y 90 a los más ancianos de las comunidades (rango de 73 a 92 años). (Macera y Casanto, 2009, p.12-13). La última fuente son las festividades consagradas a su calendario determinado por las estaciones y al recuerdo del Rebelde. La fiesta principal era la que se llevaba a cabo en honor a Juan Santos Atahualpa durante el mes de julio y en octubre, a Josecito. Se ejecutaba una danza central llamada Amasheetaantsi, en la cual participaba el mismo Juan Santos Atahualpa. Al desaparecer, su lugar lo ocupaban las autoridades de la comunidad y asimismo se aunaban los yaneshas, los piros, etc. Casanto precisa que antes de la década de los 60 la fiesta convocaba multitudes, no obstante, desde inicios del siglo XIX la fiesta tuvo graves dificultades para realizarse por las represiones adventistas, quienes han logrado someter religiosamente a la población.

La obra tiene varios aportes muy interesantes. Básicamente, la labor de Casanto se divide en 4 partes: 1) la enumeración de guerreros mitológicos/históricos; 2) la genealogía heroica (Juan Santos Atahualpa y su hijo Josecito); 3) ac- 
ciones de guerra y de su prédica religiosa; y 4) la acción de Josecito, su gobierno y su prédica. La galería de guerreros es una de los capítulos más bellos del libro, pues atiende una realidad que desborda los parámetros de la lógica occidental y nos sumerge en la cosmovisión asháninka: la conversión de los guerreros en animales, árboles y fenómenos de la naturaleza mediante los rituales mágicos desencadenados por el consumo del tabaco para efectuar sus hazañas bélicas, que no diferencian entre la historia y la mitología. Sin embargo, tenemos reparos en aceptar varios puntos cruciales de la versión asháninka de la rebelión. En primer lugar, la genealogía presentada es demasiado remota (desde mediados del siglo XVIII hasta fines del siglo XX) para ser computada de manera fidedigna solo por un medio oral (Macera incluso observa esta inconsistencia). Esta es la base de la pirámide. En segundo lugar, la evolución de las acciones son diferentes de la versión franciscana - como debe ser en realidad- hasta el punto que los vacíos no son explicables. En efecto, si Juan Santos Atahualpa es asháninka, entonces, ¿cómo se explica que las fuentes franciscanas le hayan atribuido un origen andino y viajes transcontinentales? En la versión franciscana al menos cabe la explicación de una formación jesuita, que posibilitaría un viaje al África (al colegio de la compañía de Jesús que tenían en San Pablo de Loanda en Angola) y los conocimientos de astronomía, que demostró, según los mismos rumores orales, de predecir eclipses (Loayza: 1940, p. 67-68). Casanto afirma que el Rebelde tenía raíces andinas y asháninkas. Notó las injusticias que sufrían sus semejantes y viajó al Cuzco, al anexo de Compiroshari, donde convocó una reunión para detallar la insurrección. A partir de allí da una gira en busca de adhesiones. Seis grupos étnicos deciden seguirlo: Nomatsiguenga, Matsiguenga, Piro, Amahuaca, Yaminahuaca y Amarakaire. Sostiene que la primera batalla con los españoles fue en Tarma y hubo muertos en ambos bandos. Las fuerzas del Rebelde regresaron al Cuzco y otras se fueron a Lima para conseguir nuevos contingentes. Juan Santos Atahualpa fue al Cuzco y allí reclutó fieros guerreros que lucharon contra los españoles e incluso los quemaron vivos. Ninguna de estas supuestas batallas recogidas por Casanto tiene un punto de coincidencia con los informes históricos, ni con las acciones o reacciones de los virreyes. El virrey Conde de Superunda dispuso de puestos de frontera de modo que los indígenas de la selva y los indígenas de la sierra no pudieran establecer contacto. Recordando al investigador Stern las regiones de Tarma y Jauja eran prácticamente fortines militares. Otro punto en conflicto con la versión franciscana es sobre la muerte de Juan Santos Atahualpa. En la versión asháninka fue asesinado como consecuencia de una batalla con los españoles. El Rebelde festejaba una victoria con chicha de maíz y en ese descuido fue atacado. Lograron replegarse, pero el Líder había sido herido de gravedad. Incluso se dio tiempo para dar un discurso político antes de su agonía. Les habló a todos en sus propios idiomas antes del fin (en esto sí concuerda con la versión franciscana en que Juan Santos Atahualpa hablaba varios idiomas). 
Esta desaparición motivó a los realistas a perseguir a los rebeldes acéfalos. Las fuerzas del virrey entonces aplicaron una estrategia de conciliación, pero fueron derrotados con la magia de los guerreros tabaqueros en batallas mitológicas. El liderazgo recayó en la viuda Martina Márquez Zumaeta y luego en el hijo tullido de Juan Santos Atahualpa: Josecito, que después de luchar con los españoles que lo perseguían fue un líder de paz hasta su muerte. Según Casanto, los asháninkas han dejado de adorar a sus dioses tradicionales por la prédica de los adventistas, pero no han podido desterrar el recuerdo de Josecito. No obstante, varias preguntas se pueden formular: ¿Por qué solo hemos sabido de Josecito con las recopilaciones de Casanto? ¿Por qué otros investigadores solo recogieron las versiones diversas de la muerte de Juan Santos Atahualpa y no la versión general de su rebelión? ¿Por qué Varese no escuchó de la versión asháninka y no recogió estas novedades de hace siglos, puesto que él convivió con ellos? La respuesta requiere nuevos estudios de campo que el futuro deparará. En síntesis, el Juan Santos Atahualpa asháninka que nos presenta Casanto es tan fantasmal como el presentado por los franciscanos, incluso más porque al menos del último existen documentos de las reacciones de los virreyes para sofocar la rebelión y, por lo tanto, tenemos una línea segura de los acontecimientos históricos. La versión oral de los asháninkas no nos ofrece corroboraciones; por el contrario, su historia se mezcla con la maravillosa mitología de sus guerreros.

\section{Conclusiones}

Hay tres tendencias en la historia del Perú acerca del estudio de la rebelión de Juan Santos Atahualpa. La primera es una vertiente negativa de raíz franciscana, letrada y de ideología religiosa (José Amich, José de la Riva Agüero, Fernando Rodríguez Tena, P. Bernandino Izaguirre, P. Dionisio Ortiz, etc). La segunda vertiente (que es la más fiable) es académica, desarrollada desde una perspectiva histórica algunas veces hiperbólica, que exalta la figura del rebelde como un héroe invencible (Francisco Loayza) y otras veces, despectiva (Vargas Ugarte). Entre estos dos extremos se desplazan otros historiadores (Daniel Valcárcel, Flores Galindo, Juan José Vega, etc.), antropólogos (Stefano Varese, Fernando Torres López, Alonso Zarzar) y periodistas (Mario Castro Arenas). Una tercera y última tendencia que podemos agregar es la apoyada en la oralidad (recogida por Enrique Casanto) que es una versión de la rebelión desde la perspectiva de los asháninkas. La visión global de las tres vertientes nos da una visión más amplia del rebelde como un personaje histórico antecesor de Túpac Amaru II, cuya rebelión no pudo extenderse más allá de las fronteras de la ceja de selva. Su calidad de precursor es la base de su importancia. Fue un líder nato que supo unir en un proyecto independentista múltiples etnias y propulsó una autonomía política y exigió un clero autóctono, propuestas audaces y progresistas para su época. De su ideología y su milenarismo sabemos tan poco, 
que toda reflexión caería inevitablemente en el campo de las especulaciones, lamentablemente incomprobables.

\section{Referencias bibliográficas}

Amich, J. (1988). Historia de las misiones del convento de Santa Rosa de Ocopa. Iquitos, Perú: Monumento Amazónica.

Castro, M. (1973). La rebelión de Juan Santos. Lima, Perú: Milla Batres.

Dager, J. (1995). Conde de Superunda. Lima, Perú: Brasa.

Flores Galindo, A. (1998). Buscando un inca. Lima, Perú: Horizonte.

Loayza, F. (1942). Juan Santos, el invencible. (Memorias del año de 1742 al año de 1755). Lima, Perú: Los Pequeños Grandes Libros de la Historia Americana.

Macera, P. \& Casanto, E. (2009). El poder libre asháninca. Juan Santos Atahualpa y su hijo Josecito. Lima, Perú: USMP.

Mendiburu, M. De (1960). Diccionario bistórico biográfico peruano. Primera parte. Tomo XIV. Lima, Perú: Egesa.

Millones, L. (1995). Perú colonial: de Pizarro a Túpac Amaru II. Lima, Perú: Fondo Editorial de Cofide.

Orellana, S. (1974). La rebelión de Juan Santos o Juan Santos el Rebelde. Huancayo, Perú.

Ortiz, D. (1961). Satipo, Pangoa, Gran Pajonal. Lima, Perú: San Antonio.

Riva agüero, J. De la (2010). Paisajes Peruanos. Lima, Perú: Empresa Editora El Comercio.

Valcárcel, D. (1946). Rebeliones indígenas. Lima, Perú: 1946.

Varese, S. (2010). La sal de los cerros. [4. ${ }^{a}$ Ed.]. Lima, Perú: Fondo Editorial del Congreso del Perú.

Vargas, R. (1966). Historia General del Perú IV. Lima, Perú: Carlos Milla Batres.

Vega, J. (2004). El Perú: historia de sus luchas libertarias. Lima, Perú: Universidad Nacional Enrique Guzmán y Valle. La Cantuta.

Torre, A. (2004). Juan Santos Atahualpa. Lima, Perú: PUCP. Fondo Editorial.

Santos, F. (1992). Anticolonialismo, mesianismo y utopia en la sublevación de Juan Santos Atahualpa, siglo XVIII. En Opresión colonial y resistencia indigena en la alta Amazonia. Quito, Ecuador: Cedime.

Stern, S. (1990). La era de la insurrección andina, 1742-1782: una reinterpretación. En Resistencia, rebelión y consciencia campesina en los Andes. (pp.50-81). Lima, Perú: IEP.

Zarzar, A. (1989). Mito, utopia y milenarismo en el pensamiento de Juan Santos Atabualpa. Lima, Perú: CAAP. 